\title{
O CONSELHO DE EDUCAÇÃO DA FIEMG E SUAS DIRETRIZES PARA A EDUCAÇÃO BÁSICA PÚBLICA
}

\author{
Joelma Lucia Vieira Pires \\ Universidade Federal de Uberlândia - UFU
}

\begin{abstract}
Resumo
O objeto deste artigo é a análise das diretrizes para a educação básica pública do Conselho de Educação da Federação das Indústrias do estado de Minas Gerais (FIEMG). Nosso objetivo é analisar a intencionalidade dos empresários relativamente à educação expressa nos documentos do Conselho. A criação do Conselho de Educação ocorreu na conjuntura de capitalismo neoliberal baseado na constituição da hegemonia das corporações transnacionais e na reconfiguração do poder do Estado. Essa conjuntura tem como característica a ascendência dos gestores do setor privado no Estado, políticos-empresários integram o Estado e operam a sua reforma. Eles são legitimados no Estado como referência de competência, de êxito e de eficiência e são considerados imprescindíveis para o funcionamento dos serviços públicos de acordo com a lógica do setor privado. A educação pública é atingida pela racionalidade neoliberal cujo objetivo é desconstruí-la como direito social e integrá-la à lógica do mercado como mera mercadoria com valor econômico.
\end{abstract}

Palavras-chave: Conselho de Educação da FIEMG, setor privado, Estado, Educação Básica pública.

\begin{abstract}
The object of this article is to analyze the guidelines to the public education at basic level elaborated by Education Council of the Trade Federation of the State of Minas Gerais (FIEMG). Our objective is to analyze the businessmen's intentionality relatively to the education in the Council's documents. The creation of the Education Council ocurred in the situation of neoliberal capitalism based on the hegemony of transnational corporations and at the reconfiguration of the State's power. This context has as characteristic the ascendance of the managers of the private sector at the State, politicians-managers which integrate the State and works in its improvement. Their are legitimated in the State as a ideal of proficiency, success and efficiency, considered indispensable to the appropriate operation of the public services according with the logic of private sector. The public education is achieved by the neoliberal rationality which objective is it's desconstruction as a social right, and integrating it into the logic of the market as a mere commodity with economic value.
\end{abstract}

Keywords: Education Council of FIEMG, Private sector, State, Basic public education 


\section{Introdução}

O objeto deste artigo é a análise das diretrizes para a educação básica pública do Conselho de Educação da FIEMG. Nosso objetivo é analisar a intencionalidade dos empresários relativamente à educação expressa nos documentos do Conselho. Para tanto, temos como referência as seguintes questões: qual o motivo de uma instituição que representa os empresários criar um Conselho de Educação e qual a sua função? Esse Conselho apresenta quais diretrizes para a educação básica pública?

$\mathrm{O}$ artigo é parte da elaboração de uma pesquisa acadêmica financiada pela Fundação de Amparo à Pesquisa do estado de Minas Gerais (FAPEMIG) por motivo de aprovação de acordo com o Edital de Demanda Universal 01/2017. Tal pesquisa é intitulada o Conselho de Educação da Federação das Indústrias do estado de Minas Gerais.

A pesquisa é qualitativa e fundamentada no método histórico-dialético. Logo, a produção dos dados é baseada na orientação teórica considerando o objeto de estudo em suas diversas dimensões. Dessa perspectiva, os dados foram constituídos por meio de documentos primários e secundários da FIEMG e do seu Conselho de Educação, especificados na elaboração do artigo e nas referências bibliográficas. O acesso aos documentos foi possível por meio de visita à FIEMG e de pesquisa no seu Centro de Memória.

Dessarte, reconhecemos a possibilidade de a teoria ser reelaborada de acordo com os dados e a vivência da pesquisadora no contexto da pesquisa no processo de apreensão da realidade. Consideramos a articulação da teoria com o objetivo da pesquisa e a metodologia. Embora as questões tenham sido elaboradas previamente para a orientação da investigação, a coleta de dados não foi feita com o objetivo de respondê-las, privilegiamos a possibilidade de sua problematização e reelaboração em relação aos dados coletados e, posteriormente, organizados e analisados (BOGDAN; BIKLEN, 1994).

$\mathrm{Na}$ organização deste artigo priorizamos a análise crítica dos documentos da FIEMG e do seu Conselho de Educação, assim como os que apresentam relação com eles, buscamos compreender não somente a conjuntura de origem histórica e política de tais documentos, mas, sobretudo, o que eles expressam como possível referência de ingerência dos empresários no Estado. Procuramos identificar nos documentos a intencionalidade dos empresários com a educação pública.

Ademais, neste artigo tais documentos da FIEMG são analisados de acordo com a produção acadêmica que contribui na compreensão da realidade política, econômica e social na qual se insere o objeto. Portanto, um diálogo constante entre os dados coletados por meio dos documentos e a produção acadêmica é constituído.

$\mathrm{O}$ artigo é elaborado em quatro seções. Na primeira seção, buscamos compreender as mudanças políticas e econômicas em nível nacional e internacional, considerando as repercussões para a educação básica pública. Para tanto, observamos o processo de desagregação do Estado Clássico e a constituição da hegemonia das corporações empresariais transnacionais com elevadíssimo grau de concentração do capital em um 
contexto de globalização da organização produtiva, configurando o capitalismo neoliberal. Nessa conjuntura, a educação escolar pública é apropriada pelas corporações transnacionais como uma das Condições Gerais de Produção. Na segunda seção, identificamos uma tendência de ocupação do Estado pelos empresários. Consequentemente, analisamos a criação do Conselho de Educação da FIEMG como composição da expansão da privatização da educação pública. Na terceira seção, examinamos a intencionalidade dos empresários relativamente à educação expressa nos documentos do Conselho de Educação da FIEMG. Analisamos a tendência de adequação do funcionamento das escolas públicas ao propósito de privatização. Na quarta seção, elaboramos as considerações finais.

\section{A transnacionalização do capital e a reconfiguração do poder do Estado}

A educação escolar nunca deixou de ser considerada necessária ao desenvolvimento econômico na sociedade capitalista e, por conseguinte, sempre foi objeto de interesse do setor privado. Embora tal setor a influenciasse no contexto de predominância do Estadonação, esse assumia maior protagonismo nas decisões quanto à referida educação, uma vez que a sua configuração de exercício do poder era outra.

Conforme Bernardo (1986 e 1998), em uma primeira fase do capitalismo, o Estado teve papel importante na formação de um contexto propício ao desenvolvimento, incluindo até o próprio aparecimento das grandes empresas. Em vista disso, as Condições Gerais de Produção constituíam o principal campo de existência do Estado. Nos dias atuais, o elevadíssimo grau de concentração do capital atingido pelas grandes empresas, as permite inter-relacionarem-se diretamente e, portanto, ocuparem-se das Condições Gerais de Produção sem necessitarem da intervenção do Estado. Além do mais, o Estado é nacional, enquanto as grandes empresas transnacionalizaram-se. Em suma, o processo de desagregação do Estado Clássico foi acelerado pela transnacionalização da economia, a partir da década de 1960. Tal transnacionalização aponta a constituição de uma rede pluricentrada de pólos de poder, em que a hegemonia cabe diretamente às maiores empresas. As companhias transnacionais são elas mesmas o mais importante poder na época atual.

Nas épocas em que as empresas estavam relativamente isoladas uma das outras quanto ao seu processo de produção prevalecia entre os capitalistas de cada uma delas um relativo isolamento e elevada diferenciação recíproca. A apropriação particularizada do capital constituía a forma mais importante e o processo global de produção ainda não era suficientemente integrado. Nessa fase a burguesia predominava. A globalização do processo de produção em escala mundial indica a integração das empresas em uma teia em detrimento do caráter particular, os mais importantes títulos à propriedade do capital são coletivos. Nesse contexto, os gestores afirmam-se como classe capitalista mais importante. Os gestores tornam-se proprietários coletivos do capital na medida em que participam da organização do processo global de produção (BERNARDO, 1987). 
As transformações do capitalismo referem-se ao processo de expansão das empresas globais e a globalização da organização produtiva internacional que aumenta a concorrência e inter-relação das empresas em uma enorme teia de interesses cruzados envolvendo parcerias, alianças, desenvolvimento comum de tecnologia de ponta e participações acionárias, aumentando o papel dessas empresas nos processos de decisão e no futuro da sociedade. Sendo assim, o poder econômico das corporações mundiais e a sua influência são cada vez mais determinantes das políticas dos Estados nacionais (DUPAS, 1996).

Nesse sentido, no Brasil, a década de 1990 é caracterizada pelo rompimento com o nacional-desenvolvimentismo fundamentado na forte presença do Estado na economia que prevaleceu entre 1930 e 1980. A partir do início de 1990, o país é submetido ao Consenso de Washington com nova orientação norte-americana. Nessa direção, rende-se às diretrizes neoliberais e à política macroeconômica derivadas delas, deixando de ter uma estratégia nacional de desenvolvimento e se submetendo à hegemonia externa, é a lógica concentradora das corporações transnacionais que comanda a nova ordem econômica. A prioridade é a inserção-integração das economias nacionais em uma estrutura de poder transnacional. O empresariado nacional perde o seu papel político na definição da estratégia nacional de desenvolvimento, somente uma fração muito restrita do empresariado local tem condições de integrar e participar dessa estrutura. Uma nova coalização política dominante é composta predominantemente pelo setor financeiro e pelos interesses estrangeiros no Brasil, embora outros representantes mais conservadores do empresariado brasileiro tenham se tornado propugnadores das políticas neoliberais. Do ponto de vista ideológico, formouse a articulação de um consenso dos empresários de todos os setores em torno da postura neoliberal (BRESSER-PEREIRA; DINIZ, 2009).

Bresser-Pereira (2018) esclarece que os capitalistas rentistas substituíram os empresários. A classe dominante é uma classe rentista associada com outra tecnoburocrática. Os capitalistas rentistas são os proprietários do capital e os tecnoburocratas fazem a gestão da riqueza usando da especulação financeira.

No Brasil, a década de 1990, foi marcada pela alteração no padrão de articulação Estado-empresariado. A tendência é a desnacionalização das empresas, baseada em um intenso processo de fusão, aquisição ou associação com grupos estrangeiros. Do ponto de vista ideológico significa a progressão de uma perspectiva internacionalista em contraposição a visão nacionalista (DINIZ, 2000 e DINIZ; BOSCHI, 2007). "Mais precisamente entre 1991 e 1997, foram adquiridas por empresas estrangeiras 96\% das empresas brasileiras do setor eletroeletrônico, $82 \%$ das empresas do setor de alimentos e 74\% das indústrias de autopeças [...]" (DINIZ; BOSCHI, 2007, p. 50).

A agenda de reformas econômicas e constitucionais neoliberais foi sustentada por uma ampla coalização centro-direita, a partir de 1995, com a desindustrialização e ampla desnacionalização da economia. Consequentemente, predominou o fechamento de empresas, falências e associações com empresas estrangeiras, traduzindo-se na ampla reestruturação do parque industrial e da estrutura produtiva do país e formando grandes conglomerados capitaneados pelo capital internacional. As corporações transnacionais 
comprimiram o espaço da empresa privada nacional. Para os empresários em ascensão, principalmente os que participavam da privatização dos grandes serviços de utilidade pública, entre outros, a identificação com a era neoliberal tornou-se o caminho mais promissor, considerando que o futuro do capitalismo no Brasil implicaria o aprofundamento do modelo de mercado, com articulação intensa com o capital internacional (BRESSERPEREIRA; DINIZ, 2009).

Como lembra Salej (apud Castro, 2016), Presidente da FIEMG a partir da metade da década de 1990, as matrizes das empresas transnacionais instaladas no Brasil davam o tom das decisões de mercado. Quanto ao estado de Minas Gerais: “[...] Muitas empresas estatais mineiras foram privatizadas e o controle delas, na maioria dos casos, em setores absolutamente importantes, ficou fora do Estado" (p. 156).

Em documento do Conselho de Educação da FIEMG é reconhecida a necessidade de a empresa nacional considerar a sua dependência de outras para a inserção na concorrência capitalista. Nesse sentido, no documento encontra-se a seguinte afirmação:

Ao se falar em luta pela competitividade a preocupação não deve se limitar aos funcionários da empresa. É preciso também olhar para o "lado de fora". Toda empresa depende da eficiência de seus fornecedores, da qualidade dos meios de comunicação e de transporte que utiliza, da produtividade dos portos, do preparo do servidor público que a regulamenta e fiscaliza, enfim, do nível de competência de toda a sociedade. Daí o conceito de custo Brasil. Precisamos educar todo o povo brasileiro para assegurarmos competitividade e prosperidade para a empresa nacional $[\ldots]^{1}$.

Em tal situação de competitividade no campo empresarial fica clara a preocupação com a educação escolar. Entre as Condições Gerais de Produção a educação é uma das condições sociais e materiais necessárias ao capitalismo para que haja trabalhadores e, por isso, passa a ser uma necessidade de investimento capitalista. Assim sendo, em nível mundial, verifica-se por intermédio de organismos internacionais a preocupação em relação a qualidade da educação básica sobretudo dos países periféricos. Nesse sentido, em março de 1990, foi realizada a Conferência de Educação para Todos, em Jomtien, na Tailândia, convocada pela Organização das Nações Unidas para a Educação, a Ciência e a Cultura (UNESCO); Fundo das Nações Unidas para a Infância (UNICEF); Programa das Nações Unidas para o Desenvolvimento (PNUD) e o Banco Mundial. Desta conferência resultaram posições consensuais, sintetizadas na Declaração Mundial de Educação para Todos, que constituíram as bases dos planos decenais de educação, especialmente dos países de maior população do mundo signatários desse documento ${ }^{2}$. Na Declaração Mundial de Educação para Todos: Satisfação das Necessidades Básicas de Aprendizagem, a educação é situada na perspectiva de empreendimento, objetivando, sobretudo, a eficácia e eficiência dos processos de ensino; levando-se em conta a cooperação internacional.

Conforme Phillips e Osborne (2020), a classe capitalista dominante compõe um restrito núcleo financeiro do sistema capitalista transnacional. Ela protege sua estrutura de riqueza 
concentrada por meio de organizações globais como o Banco Mundial, o Fundo Monetário Internacional, o G20, o Fórum Social Mundial, a Comissão Trilateral, o Grupo Bildeberg, o Banco Internacional de pagamento, entre outras associações transnacionais. Os representantes dessa classe são administradores que tomam parte ativa em grupos de política global e governamental e manipulam as leis, políticas e governos. O principal objetivo dos referidos administradores é o máximo retorno sobre investimentos para os seus clientes e para o seu próprio benefício, que pode ser alcançado por meios legais ou não. E, assim, tal classe privatiza o mundo, transformando-o em um mercado único.

Nessa conjuntura, a posição dos organismos internacionais quanto à educação escolar necessária parece ser compatível com a demanda por eficiência dos empresários quanto a esse serviço, em consonância com a sua articulação neoliberal. $\mathrm{O}$ argumento dos empresários é de que a ineficiência do serviço público significa um elemento adicional de custos para o setor privado. A convicção da necessidade de eficiência é manifestada na fala do Presidente da FIEMG, Salej (apud Castro, 2016, p. 38), que afirma: “[...] não haverá modernidade na área empresarial se o serviço público, em todos os níveis, não for mais eficiente".

Considerando a indicação de compatibilidade de interesse quanto à qualidade da educação escolar situada na perspectiva de empreendimento, são os gestores com origem no setor privado que ganham legitimidade no controle social da educação escolar pública por supostamente terem capacidade de empreendimento e êxito econômico. Logo, tais gestores são considerados indispensáveis para a administração dos serviços públicos, já que aparentemente melhor entendem do mercado e podem ajudar os sistemas educativos a saírem da improdutividade e da ineficiência que caracteriza as práticas escolares, segundo a posição dos empresários. Em virtude disso, conforme Gentili (1995), o raciocínio é: se os empresários souberam triunfar na vida (isto é, se souberam desenvolver-se com êxito no mercado) e o que está faltando em nossas escolas é justamente essa competência, quem melhor que eles para fornecer as "dicas" necessárias para se triunfar?

Assim, ocorre a naturalização da ascendência dos empresários na esfera pública, considerando a condição da permanência deles no Estado e a sua origem no setor privado. No Brasil, a tendência é o crescimento de um número significativo de políticosempresários $^{3}$ que se apropria do Estado e o instrumentaliza de acordo com a racionalidade instrumental da demanda econômica. Dessa maneira, o Estado funciona como extensão do setor privado e viabilizador da ampliação do capital.

Em consonância, a educação escolar como condição geral de produção é considerada propícia à ampliação do capital. O novo padrão de ampliação e acumulação do capital da sociedade capitalista fundamenta-se na constituição de novas bases econômicas, políticas e ideológicas e, por conseguinte, na associação da economia e da educação escolar para o objetivo de produtividade. Nessa direção, de maneira estratégica, políticos-empresários têm assumido funções de Secretários de Educação no Estado, entre outras, revelando um projeto político de redefinição do papel do Estado, embora tal intenção seja despercebida por percentagem significativa da sociedade. $O$ projeto de atuação dos gestores no Estado tem como centralidade a criação das condições necessárias à privatização dos serviços públicos, 
entre eles, a educação escolar. Essa privatização tem início quando já não existe discernimento na sociedade sobre o valor fundamental da esfera pública e ela fica subjugada à ingerência dos gestores empresariais de acordo com a lógica do mercado.

Um exemplo de atuação de um gestor político-empresário no Estado pode ter como referência Walfrido Silvino dos Mares Guia Neto ${ }^{4}$. Na condição de Secretário de Educação do estado de Minas Gerais, ele implementou o programa de Qualidade Total baseado na lógica do setor privado em escolas públicas. Esse modelo de administração da educação escolar foi tomado como exemplo nacional e internacional. ${ }^{5}$

As ações políticas dos empresários privilegiam a formulação de políticas públicas no campo da educação para a conformação das escolas públicas aos seus interesses. Para tanto, a FIEMG "escolheu a Parceria Empresa-Escola como um caminho para o fortalecimento da escola pública". "Com este objetivo a FIEMG criou o seu Conselho de Educação"6.

\section{A criação do Conselho de Educação da FIEMG}

A FIEMG representa o setor industrial do estado de Minas Gerais, foi fundada em 1933 pelos industriais mineiros Euvaldo Lodi, Américo Renê Giannetti e Alvimar Carneiro de Rezende. O Centro Industrial e Empresarial de Minas Gerais (CIEMG), o Serviço Social da Indústria (SESI), o Serviço Nacional de Aprendizagem Industrial (SENAI) e o Instituto Euvaldo Lodi (IEL) compõem a instituição (FIEMG, 2020). A FIEMG é a primeira no Brasil a criar um Conselho Empresarial de Educação. Esse Conselho foi criado em 1995 e dirigido por Evando Neiva, também fundador e diretor do Sistema Pitágoras de Ensino (CASTRO, 2016). Considerando que as ações empresariais são baseadas na eficiência e no empreendedorismo da lógica do mercado para o objetivo privado, não parece que seja coincidência que o diretor do Conselho de Educação da FIEMG no momento da sua criação tenha sido um dos fundadores do Sistema Pitágoras de Ensino, sócio-proprietário dessa instituição assim como Mares Guia Neto.

Uma afirmação em um documento da FIEMG demonstra sua intencionalidade quanto às escolas públicas, por meio do seu Conselho de Educação. De acordo com o documento "o nível de educação do trabalhador brasileiro é hoje muito baixo" numa fase em que "os avanços tecnológicos exigem uma mão-de-obra cada vez mais preparada". Para a FIEMG "a conseqüência será a gradual perda de competitividade da empresa nacional, em uma economia mundial que se integra rapidamente". Sendo assim afirma, "precisamos reverter esta tendência para o insucesso". E para isto "só existe um caminho, que é fortalecer a escola pública",

Ao mencionar a necessidade de fortalecimento da escola pública e a preocupação com a educação básica os empresários fazem um questionamento do sistema educacional e da educação escolar promovida pelo Estado no que diz respeito ao funcionamento da organização escolar e à fundamentação ideológica dos conteúdos do ensino. As suas ações na educação escolar visam a constituição de uma nova base ideológica e de funcionamento 
das escolas públicas baseada na racionalização da organização do trabalho e na produtividade do setor empresarial. A afirmação seguinte é de documento da FIEMG:

Em nosso país, dado o descaso com que se trata a questão do ensino básico em toda a sociedade, em que se pese a esforços ainda isolados da comunidade e enclaves no setor público, a elevação do nível de conhecimento da população requer um esforço conjugado do setor empresarial e educacional para prover uma escolarização básica por ora inexistente, insuficiente, ou, no melhor dos casos inadequada.

Daí o espaço e a necessidade de políticas adequadas para o ensino básico e de programas de parceria empresa-escola que permitam a rápida melhoria da qualidade do ensino básico no país ${ }^{8}$ (Grifos meus).

Dentro desse quadro, com o objetivo de participar do ensino público, o Conselho de Educação da FIEMG promoveu parcerias com o governo e prefeituras de Minas Gerais. Para influenciar as escolas a constituírem parceria foi criado um prêmio de determinado valor monetário para ser investido na escola, qual seja, "Prêmio FIEMG Nansen Araújo/Parceria Empresa-Escola Pública” (CASTRO, 2016). Em vista disso,

[...] em 1996, a Federação propôs ao governo Eduardo Azeredo (1995-1998) uma parceria intitulada Programa Adote uma Escola. Em 16 de abril de 1997, o referido governo sancionou a Lei 12.490 , que estabeleceu bases legais para a ação das empresas na adoção de escolas públicas no estado de Minas de acordo com os interesses da Federação. A referida lei instituiu a possibilidade concreta de disseminação de preceitos empresariais no espaço escolar, envolvendo medidas de caráter administrativo, infraestrutural e pedagógico nas escolas públicas de Minas Gerais (MARTINS, TOMAZ e PINA, 2013, p. 185).

Em um artigo publicado pelo jornal da FIEMG, em dezembro de 1997, Evando Neiva defendeu o comprometimento das empresas com a educação, argumentou: "Trata-se de uma nova consciência que alia responsabilidade social com visão empresarial de longo alcance" Neiva (apud Castro, 2016, p. 128). Mas, além de ser viabilizada pelos gestores mineiros, a parceria empresa-escola correspondia também ao propósito do Governo Federal. Referindo-se a "Parceria Empresa-Escola" e a pesquisa "A Escola de que o País Precisa", o vice-presidente da FIEMG Paulo Roberto Henrique afirma: "Estas duas ações se inserem no chamamento do presidente Fernando Henrique Cardoso para um crescente engajamento do setor privado na educação"9. Na ocasião, Cardoso exercia seu primeiro mandato como Presidente da República e, conforme Diniz (2000, p. 94), “[...] os industriais mantiveram, através de suas principais entidades, a postura de adesão à agenda neoliberal $[\ldots] "$.

Procurando instituir e justificar iniciativas que legitimam a nova ordem, em documento da FIEMG verifica-se a afirmação:

Por que a empresa brasileira deve se interessar pela escola pública? 
Nada de caridade ou filantropia. O empresário deve ajudar a prestigiar a escola pública em seu próprio interesse. À medida que a tecnologia avança e a economia mundial se globaliza, a competitividade da empresa nacional passa a depender cada vez mais do nível de escolaridade do trabalhador brasileiro ${ }^{10}$.

Os empresários esclarecem que as suas iniciativas quanto às escolas públicas correspondem aos seus próprios interesses econômicos privados e não parecem identificar nenhum problema quanto à sobreposição do interesse privado ao interesse público. Assim, desconsideram o significado histórico-cultural da escola pública como direito social, como conquista democrática e bem público.

Na exposição da Missão do Conselho de Educação do Sistema FIEMG é explícito que sua "razão de ser é transformar empresas e escolas em parceiros para o desenvolvimento e para a construção da cidadania". Assim, "na realização de sua missão, o conselho dará prioridade ao ensino fundamental na escola pública" $"$.

Por meio dessa afirmação percebe-se que ao propor a parceria Empresa-Escola, tendo como prioridade o ensino fundamental e enfatizando a questão da cidadania, a FIEMG visa a formação do cidadão adaptado de maneira instrumentalista à nova cultura e funcionamento do capitalismo. Para tanto, esse cidadão deve ter uma personalidade flexível e adaptável, e estar sempre apto a "aprender a aprender" desde o ensino fundamental. Ele deve ser instruído para acompanhar a inovação e para tornar-se um empreendedor preparado para qualquer eventualidade, isto é, "um ser dotado de espírito comercial"12 e capacidade adaptativa ao mercado de trabalho em constante mutação. Em vista disso, "“[...] A essência do lema 'aprender a aprender' é exatamente o esvaziamento do trabalho educativo escolar, transformando-o num processo sem conteúdo [...]" (DUARTE, 2001, p. 9). O objetivo é que a escola desenvolva competências de base vinculadas ao desenvolvimento profissional desde a formação inicial. Assim,

[...] a escola muda seu sentido: não é mais o local de assimilação e de presença frequente das grandes narrações que forjam caracteres estáveis para situações sociais bem definidas; ela é lugar de formação de caracteres adaptáveis às variações existenciais e profissionais em movimento incessante (LAVAL, 2004, p. 23).

Com tal propósito, o Conselho de Educação da FIEMG propõe a realização de uma ingerência direta no interior das escolas públicas, de maneira que a escola seja uma instituição capitalista, uma verdadeira empresa com valor econômico, cujo objetivo é a competividade e a eficácia produtiva adequada à economia globalizada. Para isso, as escolas públicas devem reproduzir a qualidade gerencial do universo produtivo. Em documento da FIEMG, verificam-se afirmações que expressam esta visão:

$\mathrm{Na}$ construção de uma parceria empresa-escola, os recursos materiais e financeiros da empresa não são o mais importante. A principal contribuição que 
uma empresa pode oferecer à educação é motivar os seus dirigentes e funcionários a trabalhar como voluntários na escola e pela escola.

Os funcionários de uma empresa representam para a escola um grande potencial de competência técnica e gerencial, quase sempre aliado a uma vontade de participar da construção de um Brasil melhor.

Por esta razão, a melhor contribuição que uma empresa pode oferecer à escola pública é motivar os seus funcionários a trabalhar como voluntários na escola e pela escola. Através do trabalho voluntário, os funcionários da empresa podem ajudar a escola: Colaborando na preparação do seu Plano de Desenvolvimento; Ajudando na sua administração e na desburocratização de regras e procedimentos; Auxiliando nos trabalhos de manutenção e conservação, colaborando inclusive na elaboração de planilha de reforma ou de adequação de prédios escolares; Formando equipes de voluntários na comunidade para a realização de pequenos serviços na escola; Dando aulas de reforço para alunos carentes; Ajudando no gerenciamento da merenda escolar; Convencendo os seus amigos e vizinhos a também colaborar na melhoria da qualidade do ensino público; Participando do Programa "Meu Irmão"13.

Dessa forma, verifica-se a tentativa de as empresas transferirem suas formas de gestão para o processo de trabalho pedagógico, por meio da inserção de seus funcionários no interior das escolas públicas. Esse movimento aponta a desvalorização dos trabalhadores da educação, assim como de suas experiências e propostas definidas coletivamente. Predomina a intencionalidade de motivação e envolvimento dos referidos trabalhadores em uma causa técnica, procurando deturpar a dimensão política da ação pedagógica. É como se a péssima condição das escolas públicas e do ensino fosse resultado das práticas inadequadas dos trabalhadores da educação (PIRES, 2019). De acordo com a lógica mercantil, a problemática técnica ou organizacional do processo de trabalho pedagógico restringe-se ao exame de sua inadequação quanto ao aumento da eficiência ou da produtividade do sistema. Para Arroyo (1979, p. 37):

[...] dando ênfase à irracionalidade administrativa do sistema, desvia-se, consciente ou inconscientemente, a atenção dos fatores estruturais, verdadeiros responsáveis dos fracassos da escola. Oculta-se que a organização da produção, a divisão técnica-social do trabalho, a distribuição da riqueza e do poder em uma sociedade são fatores condicionantes da distribuição dos recursos educacionais, da quantidade, qualidade e nível de educação que pode ser atingido em cada grupo social.

Por meio dos pressupostos da FIEMG, no que se refere à proposta de parceria empresaescola, expressa-se ainda, a indiferença quanto a especificidade do trabalho escolar. Uma das características desse processo de inserção no interior das escolas dos parâmetros da lógica empresarial é a forma de administrar a escola pública sob a perspectiva da propriedade, havendo uma negação da dimensão social. Assim, a parceria Empresa-Escola 
expressa o desenvolvimento da ação dos empresários no que se refere à educação escolar e, por conseguinte, a tentativa de dar legitimidade ao projeto neoliberal de educação.

Laval (2004) reconhece que a evolução mercantil no serviço educativo público não se limita a divulgação da ideologia neoliberal. A grande tendência é que os sistemas educativos nacionais entrem em competição mais direta em um mercado global. "A educação mundializada, se vem a se desenvolver como alguns prevêem, escaparia à soberania das nações para entrar de modo mais decisivo em uma era de homogeneização mundial dirigida pelas lógicas de mercado" (p. 119). O objetivo é a privatização das escolas e a sua transformação em indústrias de "competências".

\section{A ingerência do setor privado no funcionamento das escolas públicas}

Ao priorizar a racionalidade administrativa da escola pública, a FIEMG por meio da proposta de parceria empresa-escola do seu Conselho de Educação, busca instituir um novo ordenamento de organização e funcionamento do trabalho escolar. A escola pública deve funcionar baseada em critérios da livre concorrência do mercado contrários ao objetivo de legitimação da esfera pública. De acordo com a proposta de parceria empresa-escola do Conselho de Educação do Sistema FIEMG:

a iniciativa de construir uma parceria pode partir tanto da empresa como da escola.

Cada parceria terá a sua individualidade, que dependerá da visão dos dirigentes e funcionários da empresa e da escola, da dimensão e localização de ambas, da vontade de trabalhar cooperativamente, das afinidades de parte a parte, da qualidade das instalações físicas e do ensino ministrado na escola, das condições socioeconômicas dos alunos, entre outros fatores ${ }^{14}$.

Embora a FIEMG afirme que ao propor a parceria empresa-escola "a empresa deve respeitar a autonomia da escola, bem como as especificidades e valores da comunidade escolar formada pelo diretor da escola, professores, demais servidores, alunos e pais" ${ }^{15}$, verifica-se implicitamente na proposta de parceria empresa-escola do seu Conselho de Educação um vetor direcionado para a interferência, sobretudo, na estruturação do currículo das escolas. Com efeito, a FIEMG procura introduzir conceitos e valores produzidos na lógica do mercado e a ela orientados cumprindo a função de retroalimentação e visando um novo processo de socialização do indivíduo coerente com as necessidades do capitalismo. Nesse sentido, a FIEMG afirma:

A recuperação dos conteúdos equivalentes à escola do primeiro grau se torna tão mais problemática quanto menor é o nível de escolaridade prévia do aluno... Os currículos oferecidos pelas escolas formais, inclusive currículos dos cursos regulares ou supletivos noturnos, são geralmente irrelevantes, carregados demais 
de conteúdos, ou simplesmente mal ensinados. Daí a necessidade de programas especiais, com currículos adequados, preferencialmente ministrados no local de trabalho ou próximo ao mesmo ${ }^{16}$.

A tendência é reestruturar as escolas de acordo com o local de trabalho e como extensão da produção. Para isso, o objetivo do ensino deve ser o desenvolvimento de habilidades práticas e ligadas à vida real, em detrimento da formação acadêmica. Por intermédio de seus documentos a FIEMG demonstra que visa, ainda,

buscar a modernização dos currículos das escolas com a inclusão, entre outros, de temas como higiene, segurança, meio ambiente, contabilidade, símbolos nacionais, noções de gestão empresarial e qualidade total ${ }^{17}$.

Essa afirmação dos empresários questiona o trabalho realizado nas escolas quanto à formação dos estudantes. Para eles, esse trabalho é fundamentado em uma cultura abstrata e irreal que distancia a escola de uma preocupação real com a demanda social de conhecimentos. Para o alcance deste objetivo os documentos da FIEMG indicam o empenho em adequar o currículo das escolas ao mercado de trabalho e as suas necessidades imediatas. Diante disso, temos de considerar a observação de Forquin (1993, p. 171) de que “[...] Toda tentativa de subordinar a definição dos programas escolares a uma avaliação do grau de utilidade social dos saberes destinados a serem ensinados teria, aliás, implicações culturais devastadoras (...) isto é, a própria destruição de toda idéia de cultura [...]".

Como afirma Suárez (1995), o currículo pode ser considerado como um terreno de produção e criação simbólica e cultural que, consequientemente, atua como uma unidade geradora de sentidos, significados e sujeitos. Por isso, talvez um dos cenários educacionais onde a marca de princípio educativo neoliberal adquire maior densidade seja o constituído pelo campo de definição, colocação em ação e atuação do currículo, procurando construir subjetividades de acordo com os interesses e o projeto político global dos grupos de poder.

Suárez (1995) compreende que, os conhecimentos, valores, regras, recursos e normas de comportamento definidos pelo currículo oficial configuram, ainda que sempre de maneira contraditória e conflitiva, um mandato socializador que, ao interpelar pedagógica e ideologicamente os sujeitos, os constitui e os habilita instrumentalmente para perceber e atuar em um dado universo significativo. $\mathrm{O}$ mandato socializador do currículo representa, desta forma, a versão escolarizada do princípio educativo dominante.

A versão escolarizada do princípio educativo dominante, conforme Suárez, expressa-se ainda, por meio das formas de cooperação estabelecidas pela FIEMG no que se refere a parceria empresa-escola. Para que a empresa ajude a escola, a FIEMG determina algumas formas de cooperação que indicam a construção, no interior da escola, de princípios que legitimam a lógica do mercado, realizando assim a função de homogeneização dos indivíduos. Nesse sentido, a FIEMG afirma:

A título de ilustração, apresentamos algumas formas de cooperação entre empresas e escolas extraídas de casos reais de parceria no Brasil e em outros 
países, que foram enriquecidas com sugestões realistas oferecidas por Superintendentes Regionais da Secretaria de Estado da Educação de Minas Gerais $^{18}$.

Para a FIEMG, a empresa pode ajudar a escola:

Ouvindo o diretor, professores, alunos e pais. Discutindo com a comunidade o que se espera da escola. Encorajando a escola a tomar iniciativas para melhorar. Apoiando professores inovadores. Proporcionando treinamento para os membros do colegiado escolar. Promovendo visitas de professores e alunos à empresa. Ajudando o desenvolvimento pessoal e profissional de professores através da oferta de palestras e cursos. Convidando professores e alunos para palestras e cursos promovidos pela empresa para os seus funcionários. Premiando os melhores alunos. Premiando os professores cujos alunos se destaquem (uma forma de premiação é a doação de recursos para utilização pelo próprio professor na sala de aula). Dando destaque aos professores que apresentem os melhores índices de aprovação. Divulgando entre os seus funcionários ações administrativas e pedagógicas de relevância desenvolvidas pela escola. Oferecendo estágio para alunos e professores durante as férias escolares. Ministrando aulas e palestras especializadas em suas dependências. Ajudando alunos "problemáticos" ou "desajustados". Ajudando a formar "vencedores".

A autoimagem, a autoestima e as expectativas das crianças carentes, sugere a entidade empresarial, poderiam ser elevadas por meio do emprego de diversos recursos, tais como:

Palestras proferidas por profissionais "modelo". Visitas a empresas de diversos setores. Visitas a universidades. Doando material e equipamento para a escola. Doando assinaturas de jornais e revistas para a escola. Ampliando os laços da escola parceira com a comunidade (doar tinta ou cimento para a comunidade pintar a escola ou construir um muro é socialmente mais interessante e produtivo do que a empresa fazê-lo diretamente). Convidando autoridades e celebridades locais e de fora para visitar e/ou dar aula na escola. Motivando voluntários (inclusive aposentados) a dar aulas de reforço para alunos que delas necessitem. Cedendo funcionários para realizar trabalhos voluntários na escola. Colocando à disposição da escola - professores e/ou alunos - a estrutura de lazer da empresa, que pode incluir piscina, quadras de esporte e campo de futebol. Agindo como “embaixador" da escola junto a autoridades e órgãos do governo ${ }^{19}$.

Os empresários têm convicção de que a ingerência deles nas escolas públicas atingem estudantes que pertencem à classe trabalhadora, e sob esta perspectiva desenham o seu projeto de ação ideológico-cultural. Um de seus pontos de partida é a disseminação cultural de que a classe trabalhadora dever ser destituída de direitos. Zeichner (2013), observa que os empresários que defendem programas empresariais na educação pública não põem seus próprios filhos e netos nas referidas escolas, muito embora também deva ser considerado neste particular o aspecto dos valores da elite nacional, que deseja distanciar-se do convívio 
direto com a população. Neste sentido, Zeichner (2013, p. 86), sustenta que "Não devemos nos esquecer de que essas 'soluções empresariais' (...) trazem também consequências diretas para as crianças pobres, e não para os filhos dos empresários e as crianças de classe média e média alta em geral". O autor critica o uso das crianças pobres como cobaias.

A supracitada análise de Zeichner (2013) confirma a posição da FIEMG quanto propósito de educação escolar dos empresários somente para os estudantes pertencentes à classe trabalhadora. Segundo a FIEMG, "atuando junto à comunidade, a empresa pode desenvolver ações que beneficiem simultaneamente várias escolas":

Proporcionando treinamento gerencial para diretores de escola. Apoiando diretores e professores inovadores. Proporcionando treinamento para membros dos colegiados escolares das escolas da região. Promovendo encontros e seminários sobre educação. Promovendo a publicação de notícias de interesse para a educação. Dando publicidade a modelos de comportamento a serem seguidos pelos jovens. Promovendo torneios esportivos entre alunos. Promovendo palestras de interesse para a escola e para a educação, proferidas por pedagogos, psicólogos e especialistas diversos. Ajudando na implantação de programas de Qualidade Total ${ }^{20}$.

Segundo Frigotto (1995, p. 87), embora a palavra parceria pareça significar "troca de iguais", por meio das formas de cooperação anteriormente colocadas, é possível perceber como essa palavra "esconde um caráter antidemocrático". O que se nomeia como parceria não passa de um processo de adoção de escolas públicas por empresas, em que a centralização do controle pedagógico, antes conferido ao Estado (órgãos governamentais Secretarias de Estado da Educação), é transferido para o setor privado. Na verdade, mais do que a prioridade da empresa em financiar a escola pública, nota-se que a ênfase reside no controle das escolas. Para Evando Neiva, presidente do Conselho de Educação da FIEMG,

[...] a parceria entre uma escola e uma empresa não significa que esta última estará dando ajuda financeira à primeira".

Não queremos incentivar a ajuda financeira porque ela é limitadora. Existe outras possibilidades mais interessantes nessa parceria ${ }^{21}$.

Como se pode notar, nesse processo há a articulação do Estado com o setor privado no que se refere à educação escolar. No entanto, ao desenvolver sua ação quanto à educação, a ênfase do setor privado não se direciona ao financiamento, mas sobretudo, à reestruturação da gestão e dos processos escolares de acordo com os objetivos das empresas. Dessa tendência, pode-se inferir, que o financiamento continua sendo realizado pelo Estado. $\mathrm{Na}$ verdade, verifica-se uma articulação entre Estado e setor privado que favorece ao segundo. O setor privado é favorecido, principalmente, porque as modificações nas escolas públicas direcionadas aos seus objetivos são financiadas com recursos públicos. Há que se considerar, ainda, a atuação dos gestores do setor privado no Estado, na administração da 
educação escolar pública de acordo com os seus interesses e com o uso dos recursos públicos. Nessa direção, o papel do Estado é assegurar uma estrutura institucional favorável às práticas convenientes ao setor privado. Enquanto parte desse movimento, cabe lembrar a afirmação de Bernardo (1986) de que as Condições Gerais de Produção têm sido um campo privilegiado da existência dos gestores, em virtude da posição que lhes cabe no interrelacionamento dos processos econômicos.

Em sua condição de gestor político-empresário, Mares Guia Neto é um exímio representante da elite econômica nacional em articulação com a elite transnacional que operacionaliza o projeto dos representantes do setor privado de apropriação do Estado. A afirmação seguinte revela a sua participação no convencimento dos empresários para ampliarem as suas ações na educação pública (1993, p. 18):

Como empresários, os senhores devem apoiar os programas de adoção de escolas públicas. Tal adoção não deverá ser apenas uma forma de canalizar recursos para a Escola. Deve ser também uma oportunidade para que os empresários se familiarizem com as questões da Educação e com os problemas das classes mais desassistidas da população.

A adoção pode e deve ser conduzida de forma a motivar a comunidade a participar do dia-a-dia da escola. A presença da empresa e da família facilitará a continuidade de programas bem concebidos em períodos de mudança de governo. A experiência gerencial dos empresários poderá ainda ser de grande valia para as escolas públicas motivadas em aperfeiçoar a sua administração.

Analogamente, percebe-se por meio dessa afirmação que o fato de incentivar a adoção de escolas por empresas tem relação com a construção de um espaço educacional em que a administração dos processos pedagógicos contribuam, sobretudo, para uma mudança nas formas de pensar e agir dos trabalhadores da educação, da comunidade e, por conseguinte, dos estudantes da classe trabalhadora que frequientam as escolas públicas. Além disso, entende-se que o fato de a sociedade se convencer da necessidade dessas ações do setor privado é uma garantia para que independentemente da mudança de governo essa investida do setor privado seja garantida. Gentili (1995, p. 228), lembra que os indivíduos “"[...] na medida em que introjetam o valor mercantil e as relações mercantis com padrão dominante de interpretação dos mundos possíveis, aceitam - e confiam - no mercado como o âmbito em que, 'naturalmente', podem - e devem - desenvolver-se como pessoas humanas [...]".

Assim, a proposta da FIEMG de inclusão no currículo de noções como gestão empresarial e qualidade total e sua expectativa de que a parceria empresa-escola venha a favorecer uma mudança cultural no processo de formação dos estudantes e, por conseguinte, da sociedade, fica evidente na seguinte afirmação do Conselho de Educação do Sistema FIEMG: "Ao longo dos próximos anos, algumas escolas públicas, estaduais e municipais de Minas Gerais terão condições de motivar e ajudar pequenas e médias empresas a implantar programas de Qualidade Total". ${ }^{22}$

Os gestores não parecem ter nenhuma dúvida quanto a sua capacidade de ação no âmbito do Estado para constituir a educação pública de acordo com os interesses do setor 
privado. Aliás, eles não vislumbram outra possibilidade de funcionamento da educação pública que seja diferente da lógica do mercado. Por isso, afirmam que as escolas públicas terão condições de motivar as pequenas e médias empresas a implantar programas de Qualidade Total. É possível depreender de suas ações que o objetivo comum é que as escolas públicas transformem-se em empresas dirigidas por gestores do setor privado com o pessoal docente integrado na classe trabalhadora.

De fato, a apropriação do Estado pelo setor privado nunca foi tão real e oficializada como o único caminho possível. Assim, “[...] nossa própria tarefa de defesa da educação pública torna-se cada vez mais complexa [...]" (GENTILI, 1995, p. 229). A dificuldade de defesa da educação pública é clara devido a força notável do meio empresarial e da colonização de importantes órgãos do Estado que deveriam agir em função de resistência. Zeichner (2013) aperfeiçoa a análise concluindo que: “[...] a própria ideia de educação pública (...) corre sério risco [...]" (p. 121), e podemos dizer que para além de sua substância e caráter, até mesmo quanto a sua existência.

A implementação do programa de Qualidade Total nas escolas da rede estadual de ensino com a atuação de Mares Guia Neto como Secretário de Educação revelou não somente a ingerência da lógica do setor privado na educação pública. Mas, além disso, expôs a articulação e a hegemonia dos gestores do setor privado em nível transnacional no sentido de ampliação do capital por meio das Condições Gerais de Produção e, possível privatização da educação escolar (PIRES, 2000). As suas estratégias de apropriação do Estado como "guardião do interesse privado"23 inclui a relação da implementação do programa de Qualidade Total com a parceria empresa-escola, entre outras. A intencionalidade de viabilização da parceria empresa-escola é inerente à implementação da Qualidade Total, ambas significam a clareza e a objetivação das ações dos empresários para impor os seus interesses.

Conforme Bresser-Pereira (2014), o complexo de inferioridade colonial associado à dependência são características das elites empresariais e intelectuais brasileiras alienadas, a respeito do que converge Souza (2017). Essas elites se subjugam às elites hegemônicas mundiais para garantir as suas vantagens em prejuízo aos assalariados do seu país. "O resultado é a adoção pelo país dominado de políticas econômicas antinacionais - políticas que não atendem ao desenvolvimento nacional e que não interessam ao país, mas aos países dominantes" (p. 206-207).

Outro aspecto que se pode verificar por meio das formas de cooperação de parceria empresa-escola estabelecidas pela FIEMG é a ênfase no princípio da competição por meio da premiação daqueles que sobressaem na atuação em favor da legitimidade do mercado. Nesse sentido, na conferência de entrega do prêmio parceria empresa-escola da FIEMG, realizada no dia 5 de dezembro de $1996^{24}$, foram premiadas as cinco melhores empresas e escolas públicas que mantêm parceria. O presidente da FIEMG, Salej (1996), destacou o "espírito de competição" e a "efíciência no gerenciamento das escolas públicas". Por meio da premiação estimula-se a produtividade e a eficiência, bem como a competitividade partindo do pressuposto de que a crise se deve ao fato de os sistemas institucionais dependentes da esfera do Estado não atuarem como mercados. $\mathrm{O}$ fato de as escolas que 
sobressaem nesse processo de parceria receberem prêmios, que segundo o presidente da FIEMG, Salej (1996), "é em dinheiro e equipamentos" contribui para que as escolas entrem em competição pela busca de excelência. Essa busca trata de mobilizar a competitividade entre as escolas, transferindo a educação da esfera da política para a esfera do mercado, onde a exclusão e a desigualdade se reproduzem e se ampliam. Pode-se inferir, diante do quadro apresentado, que o objetivo dos gestores políticos-empresários quanto ao processo de parceria empresa-escola é a paulatina passagem do controle das escolas públicas do Estado para o setor privado. De fato, a ascendência no Estado lhes dá a certeza de que são o Estado.

\section{Considerações finais}

O objeto deste artigo é a análise das diretrizes para a educação básica pública do Conselho de Educação da FIEMG. Nosso objetivo é analisar a intencionalidade dos empresários relativamente à educação expressa nos documentos do Conselho.

Verificamos que a criação do Conselho de Educação ocorreu na conjuntura de reconfiguração do poder do Estado Clássico e da constituição da hegemonia das corporações transnacionais. No Brasil, na década de 1990, predomina a decisão de romper com o nacional-desenvolvimentismo fundamentado na forte presença do Estado na economia. O país se submete à dominação das corporações transnacionais que comanda uma nova ordem econômica de acordo com as diretrizes neoliberais. A prioridade é a sua inserção-integração na estrutura de poder transnacional sustentada na coalizão política dominante do setor financeiro. Os empresários nacionais que tiveram condições de integração nessa estrutura de poder articularam-se consensualmente ao capitalismo neoliberal buscando garantir suas vantagens em uma rede de interesses estrangeiros.

O poder do núcleo restrito de capitalistas financeiros é sustentado por administradores que têm parte ativa em grupos de política global e governamental. Esses atuam para obter o máximo retorno para seus clientes e em seu próprio benefício, manipulando leis, políticas e governos, por meios legais ou não.

Essa conjuntura tem como característica o fortalecimento dos gestores do setor privado e a sua ascendência no Estado e, por conseguinte, no controle social da educação pública. Eles são legitimados no Estado como referência de competência, de êxito e de eficiência e são considerados imprescindíveis para o funcionamento dos serviços públicos de acordo com a lógica do setor privado.

Nessa direção, um número significativo de políticos-empresários na função de gestores integram o Estado e operam a sua reforma, assumindo cargos como Secretários de Educação, entre outras funções públicas. Esse fenômeno revela a apropriação do Estado pelos gestores do setor privado. Em vista disso, a escola como referência de fortalecimento da esfera pública é questionada e atingida pela racionalidade neoliberal. O objetivo é a sua desconstrução como direito social e a sua integração à lógica do mercado como uma verdadeira empresa de valor econômico. 
Mediante o exposto, é possível observar um processo de desagregação do Estado Clássico através de esforços por privatizá-lo. Diante disso, a educação escolar pública concentrada no Estado Clássico é de interesse das grandes empresas transnacionais que acumulam o capital, uma vez que elas ocupam-se das Condições Gerais de Produção, antes sob a responsabilidade do Estado Clássico. Com efeito, os gestores do setor privado como integrantes do processo de concentração do capital das grandes empresas transnacionais apropriam-se da educação escolar pública como um campo de expansão da privatização e da acumulação do capital.

A criação do Conselho de Educação da FIEMG nessa conjuntura é uma composição da expansão da privatização da educação pública com a ocupação do Estado pelos empresários. As diretrizes desse Conselho para a educação básica pública configuram a intencionalidade dos empresários de privatização da referida educação, correspondendo ao propósito dos capitalistas neoliberais. O Conselho de Educação da FIEMG é uma das expressões da articulação dos gestores nacionais do setor privado com o projeto internacional de privatização da educação pública e de acumulação do capital.

$\mathrm{O}$ único compromisso dessa elite nacional em articulação subjugada à elite transnacional é com a garantia das suas vantagens independentemente dos prejuízos causados aos trabalhadores do seu país e ao próprio desenvolvimento nacional. Enfim, esses gestores se reconhecem como o próprio Estado e têm convicção de que não restará nenhuma alternativa e oposição à supremacia do mercado da qual participam. Nesse sentido, é imprescindível reconhecer a articulação desses gestores políticos-empresários que ocupam o Estado com o capital financeiro rentista, o qual rejeita qualquer política que não tenha como compromisso a reafirmação da sua dominação.

\section{Notas}

1. CONSELHO DE EDUCAÇÃO DO SISTEMA FIEMG. Parceria Empresa-Escola: desenvolvimento e cidadania. Belo Horizonte. s/d. p. 4.

2. PLANO DECENAL DE EDUCAÇÃO PARA TODOS. Brasília: MEC, 1993.

3. Sobre o aumento significativo do número de políticos-empresários, ver: COSTA, Paulo; COSTA, Luiz; NUNES, Wellington. Os senadores empresários: recrutamento, carreira e partidos políticos dos empresários no Senado Brasileiro (1986-2010). Revista Brasileira de Ciência Política, Brasília, n. 14, maio/ago. 2014.

4. Além de Secretário de Educação do estado de Minas Gerais, Mares Guia Neto exerceu diversas outras funções nas administrações governamentais municipal, estadual e federal, entre elas, Ministro de Estado do Turismo, Deputado Federal, Vice-Governador, Secretário de Desburocratização e Reforma Administrativa do estado de Minas Gerais, Secretário de Ciência e Tecnologia, Secretário de Planejamento e Coordenação-Geral do mesmo estado e Secretário Municipal de Planejamento de Belo Horizonte. Quanto ao seu vínculo no setor privado, é um dos fundadores do prévestibular Pitágoras, que transformou-se no Sistema Pitágoras de Ensino, nas Faculdades Pitágoras e no grupo Kroton Educacional. Também é um dos fundadores da Biobrás, empresa de insulina (CÂMARA DOS DEPUTADOS, 2020). Mares Guia Neto participou de esquema de desvio de dinheiro público em 1998, processo conhecido como mensalão mineiro, para a campanha do então candidato à reeleição ao governo de Minas Gerais, Eduardo Azeredo. As acusações de peculato e formação de quadrilha prescreveram em 2012, quando Mares Guia Neto completou 70 anos (13 de abr. de 2017). 
5. A legitimação da atuação dos gestores no Estado pode ser reconhecida por suas participações até mesmo no âmbito acadêmico. Em 1994, Walfrido Silvino dos Mares Guia Neto proferiu Conferência no Instituto de Estudos Avançados da Universidade de São Paulo (USP), intitulada "Educação para a cidadania - O cenário da pós-modernidade".

11. CONSELHO DE EDUCAÇÃO DO SISTEMA FIEMG: parceria empresa-escola: desenvolvimento e cidadania. Folheto. p. 2).

12. Expressão elaborada por Dardot e Laval no livro "A nova razão do mundo. Ensaio sobre a sociedade neoliberal”.

13. CONSELHO DE EDUCAÇÃO DO SISTEMA FIEMG: parceria empresa-escola: desenvolvimento e cidadania. p. 2, 7 e 8. O "Programa "Meu Irmão", do Conselho de Educação da FIEMG, propõe contribuir para que as crianças economicamente desfavorecidas percebam a importância da educação, com a contribuição de um adulto que se interesse pela sua educação e pelo seu futuro.

14. CONSELHO DE EDUCAÇÃO DO SISTEMA FIEMG - parceria empresa-escola: desenvolvimento e cidadania. p. 4 e 5

15. CONSELHO DE EDUCAÇÃO DO SISTEMA FIEMG - parceria empresa-escola: desenvolvimento e cidadania p. 5

16. SEMINÁRIO INTERNACIONAL FIEMG, NOVOS RUMOS DA FORMAÇÃO PROFISSIONAL. Belo Horizonte. 13-14 nov. 1995. s/d

17. PLANEJAMENTO ESTRATÉGICO. Belo Horizonte, 1996. p. 15

18. CONSELHO DE EDUCAÇÃO DO SISTEMA FIEMG - Parceria empresa-escola: desenvolvimento e cidadania. p. 5

19. CONSELHO DE EDUCAÇÃO DO SISTEMA FIEMG. Parceria empresa-escola: desenvolvimento e cidadania. p. 5, 6 e 7

20. CONSELHO DE EDUCAÇÃO DO SISTEMA FIEMG. Parceria empresa-escola: desenvolvimento e cidadania p. 10

21. INDÚSTRIA DE MINAS. Belo Horizonte. v. 1, n. 2, nov. 1995. p. 2

22. CONSELHO DE EDUCAÇÃO DO SISTEMA FIEMG. Parceria empresa-escola: desenvolvimento e cidadania. s/d. p. 13

23. Expressão elaborada por Dardot e Laval no livro: A nova razão do mundo. Ensaio sobre a sociedade neoliberal.

24. PRÊMIO FIEMG-NANSEN ARAÚJO - PARCERIA EMPRESA-ESCOLA. Belo Horizonte, 5 dez. 1996.

\section{Referências}

agenciabrasil.ebc.com.br/politica/noticia/2014-01/justiça-livra-mares-guia-de-acusacoes-do-mensalao-mineiro Acesso em 13 abr. 2017.

ARROYO, Miguel. Administração da Educação, poder e participação. Educação e Sociedade, Campinas (SP), v. 1, n. 2, p. 36-46, jan. 1979.

BERNARDO, João. A autonomia nas lutas operárias. In: BRUNO, Lúcia, SACCARDO, Cleusa (Coords.). Organização, trabalho e tecnologia. São Paulo: Atlas, 1986. p. 103-14.

. Capital, sindicatos e gestores. São Paulo: Vértice, Editora Revista dos Tribunais, 1987.

Estado: a silenciosa multiplicação do poder. São Paulo: Escrituras Editora, 1998.

BOGDAN, Roberto; BIKLEN, Sari. Investigação qualitativa em educação. Uma introdução à teoria e aos métodos. Tradução de Maria João Alves; Sara Bahia dos Santos e Telmo Mourinho Baptista. Porto (Portugal): Porto Editora, 1994. 
BRESSER-PEREIRA, Luiz Carlos. A construção política do Brasil. São Paulo: Editora 34, 2014.

Capitalismo financeiro-rentista. Estudos Avançados, São Paulo, v. 32, n. 92, 2018. Disponível em: <https://www.scielo.br/pdf/ea/v32n92/0103-4014-ea-32-92-0017.pdf>. Acesso em: 2 out. 2020.

BRESSER-PEREIRA, Luiz Carlos; DINIZ, Eli. Empresariado industrial, democracia e poder político. Novos Estudos CEBRAP, São Paulo, n. 84, 2009. Disponível em: <https://www.scielo.br/pdf/nec/n84/n84a06.pdf>. Acesso em: 25 out. 2020.

CÂMARA DOS DEPUTADOS. Disponível em: camara.leg.br/deputados/74668/biografia Acesso em: 7 nov. 2020.

CASTRO, José de Souza. $O$ enigma Salej. Um estranho no ninho do peleguismo empresarial brasileiro. KBR Editora Digital Ltda. Greenville, 2016.

CONSELHO DE EDUCAÇÃO DO SISTEMA FIEMG. Parceria Empresa-Escola: desenvolvimento e cidadania. Belo Horizonte. s/d.

COSTA, Paulo; COSTA, Luiz; NUNES, Wellington. Os senadores empresários: recrutamento, carreira e partidos políticos dos empresários no Senado brasileiro (1986-2010). Revista Brasileira de Ciência Política, Brasília, n. 14, maio/ago. 2014. Disponível em: <www.scielo.br/scielo.php?pid=S010333522014000200227\&script=sci_abstract>. Acesso em 9 abr. 2017.

DARDOT, Pierre; LAVAL, Christian. A nova razão do mundo. Ensaio sobre a sociedade neoliberal. Tradução de Mariana Echalar. São Paulo: Boitempo, 2016.

Declaração Mundial de Educação para todos; Satisfação das Necessidades Básicas de Aprendizagem. Dois Pontos, Belo Horizonte, v. 2, n. 14, p. 68-72, dez. 1992.

DINIZ, Eli; BOSCHI, Renato. A difícil rota do desenvolvimento: empresários e a agenda pós-neoliberal. Belo Horizonte: Editora UFMG; Rio de Janeiro: IUPERJ, 2007.

DINIZ, Eli. Globalização, reformas econômicas e elites empresarias. Rio de Janeiro: Editora FGV, 2000.

DUARTE, Newton. Vigotski e o "aprender a aprender". Crítica às apropriações neoliberais e pós-modernas da teoria vigotskiana. 2. ed. São Paulo: Autores Associados, 2001.

DUPAS, Gilberto. Empresas Transnacionais, Globalização e Emprego: Oportunidades e Riscos. Coleção Documentos: Assuntos Internacionais. Estratégias das transnacionais: oportunidades e riscos. Vários autores. Instituto de Estudos Avançados (Universidade de São Paulo), n. 44, p. 4-14, abr. 1996.

EMPRESÁRIO NOTA DEZ! Parceria Empresa-Escola. Conselho de Educação do Sistema FIEMG. s/d. s./p. (Folheto).

FIEMG, mais de 8 décadas de história. Disponível em: <http://www.fiemg.com.br/hotsites/MEMORIA/>. Acesso em 2 nov. 2020.

FORQUIN, Jean-Claude. Escola e cultura; as bases sociais e epistemológicas do conhecimento escolar. Tradução de Guacira Lopes Louro. Porto Alegre: Artes Médicas, 1993.

FRIGOTTO, Gaudêncio. Os delírios da razão; crise do capital e metamorfose conceitual no campo educacional. In: GENTILI, Pablo (Org.). Pedagogia da exclusão. Crítica ao neoliberalismo em educação. Petrópolis (RJ): Vozes, 1995. p. 77-108.

GENTILI, Pablo. Adeus à Escola Pública; a desordem neoliberal, a violência do mercado e o destino da educação das maiorias. In: Petrópolis (RJ): Vozes, 1995. p. 228-252.

Como reconhecer um governo neoliberal? Um breve guia para educadores. In: SILVA, Luiz Veron da, AZEVEDO, José Clóvis de (Orgs.). Reestruturação curricular; teoria e prática no cotidiano da escola. Rio de Janeiro. Petrópolis: Vozes, 1995. p. 128-137.

INDÚSTRIA DE MINAS. Belo Horizonte: v. 1, n. 6, mar. 1996.

INDÚSTRIA DE MINAS. Belo Horizonte: v. 1, n. 2, nov. 1995. 
LAVAL, Christian. A escola não é uma empresa. O neo-liberalismo em ataque ao ensino público. Tradução de Maria Luiza M. de Carvalho e Silva. Londrina: Editora Planta, 2004.

MARES GUIA NETO, Walfrido dos. Educação e Desenvolvimento. In: CONGRESSO BRASILEIRO DE FINANCIAMENTO E DESENVOLVIMENTO, 1, 12, mai. 1993, São Paulo: São Paulo: Mimeo. ABDE, 1993.

O cenário da pós-modernidade. Coleção documentos: Educação e Cidadania. Instituto de Estudos Avançados (Universidade de São Paulo). n. 11, 1994, 14p.

MARTINS, André; TOMAZ, Adriane; PINA, Leonardo. Empresários e educação: reflexões sobre o projeto educacional da Federação das Indústrias de Minas Gerais. Educ. Foco, Juiz de Fora, v.18, n.1, p. 179-207, mar./jun. 2013. Disponível em: <www.ufjf.br/revistaedufoco/files/2014/06/texto-7.pdf〉. Acesso em 25 abr. 2017.

PHILIPS, Peter; OSBORNE, Brady. Crise: o núcleo financeiro da classe capitalista transnacional. Disponível em: https://jornalggn.com.br/crise/crise-o-nucleo-financeiro-da-classe-capitalista-transnacional/ Acesso em: 2 out. 2020.

PIRES, Joelma L. V. A proposta de parceria empresa-escola da Federação das Indústrias do estado de Minas Gerais (FIEMG) e suas diretrizes para as escolas públicas. Disponível em: <www.sbpcnet.org.br/livro/58ra/SENIOR/RESUMOS/resumo_2628.html>. Acesso em 5 maio de 2019.

Qualidade Total nas escolas públicas; uma decisão política como resposta à demanda econômica (o caso de Minas Gerais). São Paulo: Faculdade de Educação da Universidade de São Paulo (USP), 2000. 358p. (Dissertação de Mestrado, Administração Escolar).

PLANEJAMENTO ESTRATÉGICO. FIEMG. Belo Horizonte. 1996. s/d (Folheto).

PLANO DECENAL DE EDUCAÇÃO PARA TODOS. Brasília: MEC. 1993.

PRÊMIO FIEMG/NANSEN ARAÚJO - PARCERIA EMPRESA-ESCOLA. Belo Horizonte. 5 dez. 1996.

SEMINÁRIO INTERNACIONAL FIEMG. Novos rumos da formação profissional. Belo Horizonte, 13 e 14 de nov. 1995. 51p.

SOUZA, Jessé. A elite do atraso; da escravidão à lava jato. Rio de Janeiro: Leya, 2017.

SUÁREZ, Daniel. O Princípio Educativo da Nova Direita; Neoliberalismo, Ética e Escola Pública. In: GENTILI, Pablo (Org.). Pedagogia da Exclusão; crítica ao neoliberalismo em educação. Petrópolis (RJ): Vozes, 1995. p. 253-270.

ZEICHNER, Kenneth. Políticas de formação de professores nos Estados Unidos. Como e por que elas afetam vários países no mundo. Tradução de Cristina Antunes. Belo Horizonte: Autêntica Editora, 2013.

\section{Correspondência}

Joelma Lucia Vieira Pires - Professora Associada III na Universidade Federal de Uberlândia (UFU). PósDoutorado em Trabalho e Educação na Universidade Estadual de Campinas (UNICAMP) e em Educação na Universidade Estadual do Centro-Oeste (UNICENTRO/Paraná). Doutorado em Educação na UNICAMP, Mestrado em Educação na Universidade de São Paulo (USP) e Graduação em Pedagogia na Universidade Federal de Minas Gerais (UFMG).

Endereços eletrônicos: joelmapires874@gmail.com e joelmapires@uol.com.br Orcid: https://orcid.org/000-0003-2885-0456

Texto publicado em Currículo sem Fronteiras com autorização da autora 